\section{Surviving and Thriving in an Acting Leadership Position}

\section{Gregory MacAyeal}

Gregory MacAyeal is Curator of the Music Library, Northwestern University Libraries, Evanston, Illinois.

Correspondence concerning this column should be addressed to Marianne Ryan, Dean of Libraries, Loyola University Chicago, 1032 W. Sheridan Road, Chicago, IL 60660; email:mryan21@luc.edu.
Excelling at one's job can be a challenge. Trying to do it for two jobs-concurrently-can be beyond difficult, yet that situation is not uncommon in evolving organizations that utilize acting appointments to bridge gaps during periods of change. In this column, Greg MacAyeal outlines the many facets of acting appointments-both the positive and the less so. MacAyeal provides much food for thought for those who may be tapped to take on such roles or are already negotiating their way through them. His insights are worthy of consideration by anyone who is juggling an acting position or thinking about doing so, as well as by administrations who rely on this mechanism during times of transition.-Editor

I

n most organizations, interim employment assignments are not uncommon. While the for-profit world makes use of interim assignments to enable certain kinds of change or growth, higher education tends to use "acting" positions in a different way. In the business world, for example, there are individuals who make careers out of interim managerial assignments. Such people are hired guns who can step in, produce a desired or prescribed result, and head off into the sunset. Acting positions in higher education, however, tend to be filled by individuals who are already employed by the college or university. In most instances, a person filling an acting role (henceforth referred to as the actor) expects to continue to be employed by the same institution once the acting assignment has concluded. The responsibilities of the actor's "old" job, along with those associated with the acting position, are expected to be met with equal attention. Practically speaking, this is nearly impossible, but the work is there and needs to be done. Filling these positons may be a comparatively fast and simple process, which is advantageous to the organization. However, realizing success as an actor is not fast and can be riddled with complications. It is highly beneficial to the organization to support the actor. This article will describe potential hazards and suggest strategies to enable success in interim employment.

\section{BACKGROUND}

The library and managerial literature includes a handful of pertinent articles on this subject. Lisa German offers a practical approach in day-to-day leadership. She suggests that actors need to view their new roles with enthusiasm, and proceed with the intent to advance established goals, as opposed to simply maintaining operations. ${ }^{1}$ Lynn Chmelir offers her perspective on being an interim director, something 
that happened twice in her career. In both situations, she was hired from the outside as an interim director, and her comments reflect the need to add stability to an unsettled situation. ${ }^{2}$ Her commentary builds upon another engaging essay authored by Gail Munde, whose experience is in a large academic library. She describes "lessons learned" and covers time management, perceptions, and the experience of suddenly finding herself on the playing field of the whole university, not just the library. ${ }^{3}$ Offering additional advice, Sandra Shell demonstrates how personal management style can positively impact a short-term assignment. She advises potential actors to be informed, do the work that needs to be done, and allow themselves to make mistakes while emphasizing the growth opportunity available to them. ${ }^{4}$ Sandra Weingart's article provides a carefully written case study regarding her time as an academic library acting director. She describes the experience of suddenly leading a unit without the benefit of established goals. ${ }^{5}$ Pat Newcombe and James Donovan describe a career path that leads from acting to permanent employment. ${ }^{6}$ Overall, these excellent texts suggest a few common themes in the areas of communication, administrative support, time management, expectations and perceptions, and ultimately the potential benefits of accepting acting assignments. I will address these themes and others as informed by my own experience in an acting role.

I was named acting head of the Music Library at Northwestern University, an appointment that lasted roughly one year. At the end of my appointment, I was named permanent curator of the Music Library. Prior to my time as acting head, for six years I held the position of assistant head of the Music Library.

The title of Curator that I now hold came about as the result of a large-scale reorganization process. Beginning in 2014, Northwestern Libraries embarked on a robust plan with the stated purpose to revision the library as an outwardfacing organization. A central goal of the reorganization was to consolidate like kinds of work into single workgroups across the library. For example, in the previous organization, the Music Library was a single department with responsibilities that included stacks management and cataloging. In the new structure, both of these functions were transferred to other units, bringing similar work together. The Music Library became a more service-focused unit. No longer a stand-alone department, it is now a unit within a larger workgroup called Distinctive Collections, but still keeps its mission of maintaining a world-class collection of music materials. Throughout the library, many staff members took on new or revamped responsibilities as a direct result of the reorganization. Several acting positions were created. My experience was not unique.

\section{ALLEGRO NON TROPPO (FAST, BUT NOT TOO FAST)}

As stated above, one benefit of appointing an existing staff member to an acting positon is that it can happen relatively quickly. The organization can begin working promptly where there is need or in entirely new areas. However, the downside to speed and flexibility is a deficiency in long-term planning. For newly created positons in newly formed units, acting leaders may begin their work with unclear relationships to administration, staff, and new reports. Administration may not have the time to look carefully at the strategic needs of new units, and thus may not be immediately able to deliver complete job descriptions or define competencies.

Another challenge is that newly formed units with acting leaders may not have the benefit of established access to materials and organizational resources. Acting unit leaders may be asked to hit the ground running with little more than an outline of their responsibilities. Budgets, workflows, and policies may not exist at the onset but instead come in time. The need to quickly solve practical, on-the-ground problems can cause a delay in long-term or strategic planning. This in turn can hinder the development of a vision for a permanent appointment. Solutions for practical problems can be definitive and stand as the lasting approach to addressing a particular need. It becomes difficult to make a change to that solution even when the opportunity to think strategically finally arrives.

\section{COMMUNICATION}

A key point taken from the existing literature is that excellent communication is imperative. Think of the actor as the central point in a communication chain that flows in a bidirectional manner, away from the actor to both administration and to staff. This of course is true in any leadership position, particularly in those often referred to as a mid-level. From the perspective of the actor, it is important to allow reporting staff to communicate openly and freely. If the actor is stepping into a breach, staff will express their concerns. The need to allow reporting staff to communicate their concerns is vital even when no immediate solution is clear or available. Especially in times of transition, people fundamentally feel the need to be heard.

\section{MANAGING EXPECTATIONS}

The impermanence of an acting role creates a unique situation related to expectations. Will the actor be expected to significantly advance already-established goals? Will the actor take on more of a maintenance role, with work limited to sustaining routine tasks? Staff may wonder if they should take the actor seriously, or ignore the actor and wait for a permanent hire. Administration can help tremendously by firmly communicating expectations, both to the actor and to the reporting staff. It is important for everyone to have a shared understanding.

Administration may expect an actor to continue to work at a high level. In instances where the expectation is to move 


\section{MANAGEMENT}

unit goals forward quickly, the actor may not have time to develop relationships naturally. It may be difficult to know how to delegate work. Most likely, the actor will tend to work especially hard with those staff who will address pressing needs, but those needs may not be critical from a strategic perspective. The urgency of short-term gains can negatively impact long-range goals. In such a myopic situation, truly important relationships can go undernourished.

\section{MANAGING PERCEPTIONS}

Reporting staff will need to see the actor as a resource, no matter what expectation is understood, and how the actor is perceived is very important. If an internal appointment, the actor will undoubtedly carry some existing perceptions. The actor may also need to respond to perceptions related to the predecessor, if there is one. When perception of the predecessor is positive, everyone will want the actor to work in the same style. When negative, there will be hope for a departure. Good and bad, fair and unfair, how the actor is perceived defines how the actor will be treated. Some people may find it difficult to define themselves in new roles. The actor may be required to treat others differently because relationships have been redefined. Asserting an identity beyond any existing perception is a burden the actor must overcome, but one of vital importance.

\section{AUTHORITY}

More responsibility should lead to more authority, but this does not always happen-or happen fast enough. If we think of authority as a construct of responsibility, trust, and acceptance, we see that authority is both granted (by those who assign responsibility) and allowed (by those who accept direction). Administration will likely support the decisionmaking responsibility of the actor, but the actor will still need to earn administration's trust. It may take some time for administration to fully trust an actor to make important decisions. Without trust, the staff will not allow the actor to retain authority without some kind of intervention. If this intervention is required before the actor has gained the trust of administration, lasting problems may develop. Unresolved trust issues will impede the actor's authority, which can create a toxic situation. For the actor to be successful, the actor's authority must be accepted by everyone.

\section{ONE PERSON, TWO JOBS, AND HOW TO FILL THE VOID}

Many times, an actor will end up with two jobs. Administration may seek to reduce the work load of the actor, but often not much can done. Prior responsibilities will still need to be addressed. An acting position implies a vacancy, and these responsibilities will likely be distributed across the actor's permanent home unit and possibly the temporary unit. To fill the vacancy, unit responsibilities might be redistributed so staff members take on extra work. Addressing most critical needs can necessitate staff working beyond their strengths or primary areas of responsibility.

While it's wonderful to have staff who are willing to take on extra work, an incorrect sense of ownership can develop. It may create a "job creep" of sorts that will ultimately produce flawed workflows and enable on-the-fly decisions to become policy. When the time comes to reevaluate responsibilities and workflows, staff who have taken on extra work may not want to relinquish it, even to other more appropriate staff. Job creep can become permanent, with ill-suited employees juggling an odd array of duties.

\section{THE SUCCESSFUL ACTOR}

Completing an acting appointment with a successful outcome depends on a complex set of interdependent factors. How well administration supports the actor is key, as is how the actor develops relationships. Staff will help both themselves and the actor, if they are able to accept the actor and maintain reasonable expectations.

Administration can help actors by taking these steps:

- Setting well-defined and manageable goals. The sky will seldom be set as a limit for anyone in an acting role. Administration will help the organization by broadly communicating reasonable expectations which should align with the parameters of the temporary situation. With periodic review, goals can be altered to fit evolving needs.

- Setting the tone. By making sure the organization knows that the actor will be supported, administration will be able to establish authority and encourage staff to feel that the unit's success is a priority.

- Establishing a path to resources early in the actor's tenure. With newly defined roles, it may be unclear what budgets, facilities, and staff are available to help the actor. Having these questions answered early will help ensure that efforts are well supported.

- Making a timeline. Crucial to setting reasonable goals, an initial timeline will give the organization a sense of formal structure in an otherwise uncertain setting. Timelines should be reviewed periodically.

Actors can help themselves by taking these steps:

- Actively working to keep communication lines open. Developing relationships with staff is the most important initial goal. This is crucial to having the staff believe that the actor wants to listen and values all members of the unit.

- Asserting themselves. Actors need to communicate their expectations based on goals set by the organization and 
the unit. They should allow their natural style to emerge without being overly critical of predecessors. Aside from not fully understanding the predecessor's decisions, actors may undermine the relationships they are trying to improve.

- Delegating appropriately. By assigning work where it is best suited, the long-term health of the unit will be strengthened. Actors must resist the urge to assign work solely to staff that are available, are friends, or have worked well in unrelated situations.

Staff can help actors by taking these steps:

- Allowing actors to be themselves. By resisting the temptation to make comparisons, staff will allow actors' natural styles to flourish.

- Accepting that any extra work may be temporary. Taking on new areas of responsibility is most successful when it's part of a larger strategic vision. Matching personal strength and interest with need is essential and should be targeted over convenience and speed.

- Keeping expectations in check. It will take time for the actor to secure all the resources needed to complete all tasks. Patience is always a virtue.

\section{SURVIVING AND THRIVING}

The upside for the actor is potentially high. An acting role may offer the chance to grow in areas that may otherwise be unavailable. By interacting with a fuller range of staff, the actor has the opportunity to create a new workplace context for him or herself. Performing at a high level while really holding two jobs shows administration an actor's high capacity and ability to adapt. These are "soft skills" that can normally be very difficult to demonstrate. The experience may very well evolve into a permanent situation, as in my case, or it may to lead to a different opportunity. Other leadership situations may arise, and with an established track record of positive growth, leadership experience, and willingness to take on challenging work, the actor is well poised to become a viable candidate. For opportunities that arise outside of the organization, the actor's CV will reflect the additional experience.

From the administration's perspective, there is also a potential upside. Acting assignments offer a unique opportunity to test out an employee's ability to grow. With only a short-term commitment, if the acting assignment is not a good fit, administration can choose to return the actor to the original role. If the actor is competing for a permanent positon, administration will have gained valuable insight which will inform the recruiting process. The chance to evaluate a staff member with on-the-job experience in an agile setting gives administration a staffing tool unlike any other.

There is a shelf life to all acting appointments. The longer the duration of acting roles, the more difficult success becomes for both the actor and organization. Ambiguity can lead to stress, temporary measures can become lasting solutions, and time slips away on strategic goals. With administrative help, actors will be successful and provide essential help to their organizations. Ideally, both the actor and the organization will have a good experience by the conclusion of the acting assignment. No matter what follows, the actor will have grown and demonstrated new abilities, and the organization will have gained valuable knowledge on which to base strategic decisions.

\section{References}

1. Lisa German, "Making It Real-The Challenges and Responsibilities of Being an 'Acting Head," Technicalities 31, no. 1 (January/February 2011): 1, 6-7.

2. Lynn Chmelir, "Here Today, Gone Tomorrow: Observations of an Interim Academic Library Director," OLA Quarterly 18, no. 1 (Spring 2012): 6-7.

3. Gail Munde, "My Year as Interim: Six Things I Learned for Free," College \& Research Libraries News 61, no. 5 (May 2000): 416.

4. Sandra Shell, "My Experience as a Bridge," Virginia Libraries 57, no. 2 (April/June 2011): 17-19.

5. Sandra J. Weingart, "Costs and Benefits of Interim Managerial Assignments in an Academic Library," Library Management 24, no. 4/5 (2003): 237-42

6. Pat A. Newcombe and James M. Donovan, "Becoming Director: An Internal Candidate's View," Library Management 34, no. 3 (March 2013): 188-99. 